\title{
O estágio do governo eletrônico no Brasil em relação ao contexto mundial
}

\author{
Paulo Henrique Ramos Medeiros \\ Tomás de Aquino Guimarães
}

Revista do

Serviço

Público

Ano 55

Números 1 e 2 Jan-Jun 2004

\section{Introdução}

Os governos vêm se deparando com o aparecimento de novas formas de organização e de produção em escala mundial que delinearam o que se convencionou chamar de "Sociedade da Informação", baseada no conhecimento, na educação e no desenvolvimento científico e tecnológico (Kumar, 1997). Essa nova "sociedade em rede" vem redefinindo a inserção dos países na sociedade internacional e no sistema econômico mundial (Castells, 1996), tendo como consequiência, também, o surgimento de novas demandas dirigidas ao setor público, no que diz respeito ao seu próprio funcionamento.

Os governos de distintos países passaram, em décadas recentes, a operar nesse ambiente complexo, precisando, portanto, adaptar-se a novas realidades, como a globalização e a era do conhecimento, na qual foi moldada a Sociedade da Informação, contexto em que Tecnologias de Informação e Comunicação (TIC) têm papel crucial no modo como o Estado cumpre suas principais funções. As novas tecnologias mudam a abordagem da gestão pública, devendo-se levar em conta que cidadãos, empresas e demais organizações querem ter acesso ao governo de modo cada vez mais rápido e facilitado, na expectativa de que os programas governamentais estejam focados em suas necessidades.

Com a evolução do uso de computadores e dos meios de comunicação e, especialmente, da infra-estrutura da Internet, definiramse novas formas para os modelos de relacionamento Estado-sociedade que conformariam novas estruturas de governança -, cada vez mais baseados em TIC. As novas tecnologias teriam, portanto, potencial para

Paulo Henrique Ramos Medeiros é Analista de Controle

Externo do Tribunal de Contas da

União e mestre em administração pela UnB.

Tomás de Aquino Guimarães é professor do programa de pós-graduação em administração da UnB e doutor em sociologia pela USP.

Contato: paulohr@ tcu.gov.br tomas@ unb.br 
construir uma nova relação entre governo e cidadãos, ao pressupor-se que possibilitam uma administração pública mais eficiente, democrática e transparente.

O governo eletrônico - também identificado como "e-gov" ou "e-governo" - vem se mostrando como uma das maneiras encontradas pelo setor público para prestar seus serviços de modo a atender mais ágil e eficientemente às demandas da sociedade, no contexto anteriormente delineado. Identificado como uma inovação em administração, o e-gov representa, essencialmente, o provimento de acesso via Internet a informações e serviços oferecidos pelos governos.

A Internet, como veículo de aproximação do Estado com o cidadão, é o principal instrumento para a consecução dos planos de fazer o governo cada vez mais "eletrônico". A intenção, com a presença governamental na web, é tornar o aparato administrativo menos aparente de forma presencial, mas, ao mesmo tempo, mais próximo do cidadão e mais eficiente na realização de seus objetivos, com a utilização de técnicas e sistemas de informática e comunicações. Com isso, verifica-se a utilização de TIC na implementação de conceitos contemporâneos advindos da administração, a exemplo do gerencialismo na condução das organizações públicas, e mesmo um incentivo ao controle social (Sato, 1997).

Para avançar no entendimento dessas questões, o presente artigo tem como principal objetivo discutir o posicionamento do Brasil com relação aos rankings internacionais de governo eletrônico, especialmente o que vem sendo divulgado pelas Nações Unidas. Antes de promover o debate sobre o atual posicionamento do Brasil, em relação aos demais países que implementam o e-gov, o artigo apresenta seções que abordam o conceito de governo eletrônico, os programas governamentais brasileiros nessa área e a classificação das Nações Unidas para avaliar o estágio de desenvolvimento dos países nessa política. Ao final, é feita uma reflexão sobre as perspectivas para o futuro do governo eletrônico no país.

\section{O conceito de governo eletrônico}

O advento da Internet e das inovações em comunicações proporcionaram às organizações a possibilidade de migrar seus sistemas existentes em plataformas convencionais para sistemas com interface web. O esgotamento de sobrevida de sistemas legados pode ser considerado, também, um outro fator que motivou a construção de sistemas baseados na Internet - os quais conformam, na prática, o governo eletrônico. Outros aspectos que incentivaram o surgimento dessa inovação foram:

1) a necessidade de as administrações aumentarem sua arrecadação e melhorar seus processos internos; e 
2) as pressões da sociedade para que o governo otimizasse seus gastos e atuasse, cada vez mais, com transparência, qualidade e de modo universal na oferta de serviços e provimento de informações aos cidadãos e organizações em geral. Todos esses fatores encontraram na utilização das TIC uma oportunidade de inovação na execução de projetos que pudessem materializá-los.

As possibilidades de otimização de processos de governo, ou mesmo a criação de novos processos, baseados em soluções de TIC passam por princípios definidos pelos conceitos de governo eletrônico. Portanto, para que se tenha uma idéia clara do objeto de estudo deste artigo, são apresentadas algumas das definições mais utilizadas para caracterizar o governo eletrônico - "fenômeno relativamente recente que ainda não foi claramente definido" (Grande; Araújo; Serna, 2002, p. 5) e que recebe denominações como "governo digital" ou "governo virtual" (Coelho, 2001, p. 112) -, como as apresentadas a seguir:

\section{Quadro 1: Definições de governo eletrônico}

\begin{tabular}{|c|c|}
\hline Definições de governo eletrônico & Fonte \\
\hline $\begin{array}{l}\text { Governo eletrônico refere-se ao uso, por agências } \\
\text { governamentais, de tecnologias de informação (como redes } \\
\text { de longa distância, Internet e computação móvel) capazes } \\
\text { de transformar as relações com cidadãos, empresas e outras } \\
\text { unidades do governo. Essas tecnologias podem servir a } \\
\text { diferentes fins, como: melhor prestação de serviços aos } \\
\text { cidadãos, interações mais eficazes com empresas e a } \\
\text { indústria, empowerment do cidadão por meio do acesso } \\
\text { a informações ou mais eficiência na administração } \\
\text { governamental. }\end{array}$ & $\begin{array}{l}\text { Banco Mundial } \\
(2003)\end{array}$ \\
\hline $\begin{array}{l}\text { Governo eletrônico ou e-governo significa prover acesso } \\
\text { público via Internet a informações sobre os serviços } \\
\text { oferecidos pelos departamentos centrais do governo e } \\
\text { suas agências, habilitando o público à condução e à } \\
\text { conclusão de transações para tais serviços. }\end{array}$ & $\begin{array}{l}\text { National Audit } \\
\text { Office } \\
(2002, \text { p. } 1)\end{array}$ \\
\hline $\begin{array}{l}\text { O termo 'e-government' [utilizado em inglês para } \\
\text { denominar o governo eletrônico] aborda o uso de novas } \\
\text { tecnologias de informação e comunicação pelos governos, } \\
\text { aplicadas a todas as suas funções. }\end{array}$ & $\begin{array}{l}\text { OCDE }(2001, \\
\text { p. 2) }\end{array}$ \\
\hline $\begin{array}{l}\text { E-governo é definido como: utilização da Internet e } \\
\text { da web para ofertar informações e serviços governamentais } \\
\text { aos cidadãos. }\end{array}$ & $\begin{array}{l}\text { Nações Unidas } \\
(2002, \text { p. 1) }\end{array}$ \\
\hline $\begin{array}{l}\text { O termo governo eletrônico é definido como a oferta e } \\
\text { troca de informações e serviços governamentais on line } \\
\text { para cidadãos, empresas e outras agências governamentais. }\end{array}$ & $\begin{array}{l}\text { INTOSAI } \\
(2003, \text { p.3) }\end{array}$ \\
\hline
\end{tabular}

Fonte: Referências mencionadas no quadro. 
Para fins de pesquisa em governo eletrônico, vale lembrar que esse conceito encontra-se na intersecção de três áreas do conhecimento: políticas públicas, gestão organizacional e tecnologia da informação. Ao longo da história, desenvolvimentos na tecnologia têm emergido muito mais rapidamente do que a evolução em formas organizacionais e diretrizes para políticas públicas. Mesmo com essas diferenças cadenciais, esses três domínios constantemente interagem um com o outro, gerando muitas questões e conflitos sobre o que é tecnicamente possível, organizacionalmente adequado e socialmente desejável (Center for Technology in Government, 1999, p. 29).

Este trabalho espelha, portanto, preocupações contemporâneas sobre as novas formas de atuação dos governos e sobre os modos de se incrementar a governança e a democracia, podendo ser mais bem visualizado o crescimento das discussões em torno do e-gov, por meio dos eventos de âmbito internacional que vêm sendo promovidos nos últimos anos. O Terceiro Fórum Global - Fostering Democracy and Development Through E-Government, organizado pelo governo italiano em Nápoles, em março de 2001, contou com a participação de representantes de 122 países e discutiu o potencial das TIC para os governos de países desenvolvidos e em desenvolvimento, bem como a capacidade dessa inovação em dar suporte à democracia e ao desenvolvimento (Terceiro Fórum Global, 2003).

Outro evento que mostrou a importância global do tema "governo eletrônico" foi a Cúpula Mundial sobre a Sociedade da Informação, cuja primeira fase foi realizada em dezembro de 2003 em Genebra, Suíça, com a segunda etapa prevista para novembro de 2005, em Túnis, Tunísia. Essa foi a primeira reunião internacional das Nações Unidas sobre tecnologia da informação, considerando que evento similar realizado em 2000 reuniu apenas os países integrantes do G-8 e alguns poucos convidados. Em 2003, com a participação de representantes de 176 países, a Cúpula discutiu não somente o papel das tecnologias como ferramentas na Sociedade da Informação, mas também a dimensão humana que pode ser explorada com base no aproveitamento das TIC. Os resultados das discussões - com temas controversos como a governança mundial da Internet - foram explicitados por meio de uma Declaração de Princípios e um Plano de Ação com objetivos a serem alcançados pelos países até 2015 (Cúpula Mundial sobre a Sociedade da Informação, 2004). 


\section{O Contexto Brasileiro: os Programas Governo Eletrônico e Sociedade da Informação}

\section{Programa Governo Eletrônico}

Por intermédio do Decreto Presidencial de 3 de abril de 2000, conforme descreve Souza (2002), criou-se um Grupo de Trabalho Interministerial com a finalidade de examinar e propor políticas, diretrizes e normas relacionadas com as novas formas eletrônicas de interação. Informalmente, esse núcleo de pessoas ficou conhecido como Grupo de Trabalho em Tecnologia da Informação (GTTI). A criação desse grupo, ainda de acordo com Souza (2002), foi inserida dentro da política do governo para lançar as bases da criação de uma sociedade digital no Brasil. Suas ações coadunaram-se com as metas do Programa Sociedade da Informação (SocInfo), coordenado pelo Ministério da Ciência e Tecnologia. Nesse contexto, o GTTI assumiu o papel de facilitador na busca dos objetivos do SocInfo.

Para levar a efeito tais medidas, discutidas no âmbito do GTTI, o governo brasileiro lançou, em setembro de 2000, o documento intitulado "Proposta de Política de Governo Eletrônico para o Poder Executivo Federal" (Brasil, 2000b), no qual há um detalhamento de macroobjetivos prioritários e metas para o período 2000-2003. Os principais objetivos referem-se ao estabelecimento de "um novo paradigma cultural de inclusão digital, focado no cidadão/cliente, com a redução de custos unitários, a melhoria na gestão e qualidade dos serviços públicos, a transparência e a simplificação de processos" (Brasil, 2000b, p. 5). Ressalta como fundamentais "a cooperação, convergência e integração das redes e dos sistemas de informações do governo", "o uso do "peso institucional do governo' no mercado, integrando ações de compra e contratação de tecnologias da informação que possam reduzir custos unitários" e "a inclusão social e a ampliação do uso da tecnologia da informação pelo cidadão brasileiro." (Brasil, 2000b, p. 5).

O Programa Governo Eletrônico tem sido implementado com base na atuação de coordenação e mobilização empreendida a partir da Presidência da República (por meio da Casa Civil), com apoio técnico e gerencial da Secretaria de Logística e Tecnologia da Informação (SLTI) do Ministério do Planejamento, Orçamento e Gestão (Brasil, 2002). A SLTI é o órgão responsável pelo planejamento estratégico, coordenação interministerial e emissão de normas relacionadas com a área de informática. Esse arranjo está sustentado em um comitê interministerial, integrado pelos SecretáriosExecutivos (e cargos equivalentes) dos ministérios e da Presidência da República, denominado Comitê Executivo do Governo Eletrônico - Cege (Brasil, 2002). 
Com a criação do Cege, em outubro de 2000 (Brasil, 2000c), foram definidos papéis a serem cumpridos por diversos órgãos públicos e implementadas ações e normas que conformaram o ambiente institucional, no qual o e-gov se estabeleceu no país. Em termos do discurso oficial, o governo brasileiro afirma que esse comitê tem a meta de disponibilizar todas as informações e serviços governamentais na Internet, além de garantir acesso à Internet para a população brasileira.

A fim de elaborar seus documentos e projetos, o Cege instituiu, entre 2000 e 2002, Grupos de Trabalho (GT) formados por dirigentes e técnicos dos ministérios, agências e autarquias envolvidos com o programa de e-gov. Os GT funcionavam com o apoio da SLTI/MPOG e de consultores contratados.

Em 2003, foram criados oito comitês técnicos no âmbito do Cege, com a finalidade de coordenar e articular o planejamento e a implementação de projetos e ações nas respectivas áreas de competência (Brasil, 2003). Os comitês são os seguintes:

a) Implementação do Software Livre;

b) Inclusão Digital;

c) Integração de Sistemas;

d) Sistemas Legados e Licenças de Software;

e) Gestão de Sítios e Serviços On line;

f) Infra-Estrutura de Rede;

g) Governo para Governo - G2G;

h) Gestão de Conhecimentos e Informação Estratégica.

Um aspecto de interesse presente no decreto que instituiu os comitês técnicos em 2003 (Brasil, 2003) é o fato de que há previsão que o coordenador de cada comitê possa convidar, para participação nas reuniões de seu grupo, representantes de outros órgãos e entidades públicas que não aqueles que conformaram inicialmente o comitê, e, especialmente, de empresas privadas ou de organizações da sociedade civil.

\section{Programa Sociedade da Informação}

No Brasil, os projetos de e-gov dos demais entes federativos têm sido estimulados pelo progresso das iniciativas do governo federal, desenvolvidas em duas vertentes de atuação (que por vezes se sobrepõem): 1) nas diretrizes do Comitê Executivo do Governo Eletrônico, executadas por meio do Programa Governo Eletrônico e outros programas governamentais e 2) em três das sete linhas de ação do Programa SocInfo "Universalização de Serviços para a Cidadania", "Governo ao Alcance de Todos" e "Infra-estrutura Avançada e Novos Serviços".

O Programa SocInfo (Brasil, 2000a), do Ministério da Ciência e Tecnologia, fez parte do conjunto de projetos que compuseram o Plano 
Plurianual - PPA 2000-2003 e também está inserido no PPA 2004-2007. O

SocInfo constitui o principal esforço governamental para a inserção do Brasil na sociedade da informação e tem o objetivo de viabilizar a nova geração da Internet e suas aplicações em benefício da sociedade brasileira. Takahashi (2004, p. 87) afirma que o SocInfo é um programa de concepção e integração de ações, mais do que de execução verticalizada, ressalvando que, "em face das características da situação brasileira, também tem exercitado ações concretas e operacionais quando as circunstâncias demandam."

Foi lançado no Brasil, em setembro de 2000, o Livro Verde do Programa SocInfo (Brasil, 2000a), que corresponderia a uma fase inicial de discussões para a implantação de medidas rumo à sociedade da informação. Esse tipo de documento propõe diretrizes para a estruturação de infra-estruturas de comunicação, regulação, educação e universalização de acesso ao ambiente digital, bem como para o desenvolvimento de ações governamentais que também promovam o incremento da sua eficiência e da sua transparência, por meio do uso intensivo de tecnologias (Coelho, 2001, p. 112).

O Livro Verde (Brasil, 2000a, p. 11) estabelece quais são os stakeholders de interesse para essa sociedade baseada no conhecimento, destacando a necessidade de que haja a "colaboração entre diferentes parceiros nos níveis local, nacional e internacional. O compartilhamento das responsabilidades entre governantes, organizações privadas e a sociedade civil é modelo básico de apoio à sociedade da informação." Além disso, esse documento ressalta que papel importante para o êxito do SocInfo caberá às universidades e demais entidades educacionais, pelo seu envolvimento na formação de recursos humanos e na construção da indispensável base científico-tecnológica (Brasil, 2000a, p. 11).

Apesar de terem sido indicadas diretrizes para diversas áreas de atuação (sete linhas de ação no Livro Verde [Brasil, 2000a]), o Programa SocInfo não conseguiu chegar à fase de "Livro Branco", na qual seriam consolidadas as discussões entre os diversos setores da sociedade (governo, iniciativa privada, comunidade científica e Terceiro Setor) para a proposta de ações concretas. De qualquer modo, juntamente com o Programa de Governo Eletrônico brasileiro, o Programa SocInfo se constituiu, conforme menciona Souza (2002), um dos grandes programas governamentais rumo a uma política nacional para a tecnologia da informação.

O próprio Poder Executivo federal ressalta a complementaridade do SocInfo em relação ao programa de e-gov, pois "a ação do governo em tecnologia da informação e comunicação é complementar ao Programa SocInfo do Ministério da Ciência e Tecnologia que estabelece normas para a ampliação da competitividade e da produtividade" (Brasil, 2000b, p. 3-4). 


\section{O Brasil e o contexto mundial de governo eletrônico}

\section{O ranking de governo eletrônico das Nações Unidas}

Um tema que se tornou recorrente na literatura relacionada a governo eletrônico é aquele que trata das "classificações" ou "categorizações" dos estágios em que os países se encontram em seus esforços de implementação de programas de e-gov, elaboradas a partir da análise dos portais de governo e suas funcionalidades. Por tratar-se do mais abrangente e recente ranking de e-governo disponível, será apresentado nesta subseção o modelo das Nações Unidas (2003), conforme Quadro 2.

\section{Quadro 2: Modelo de medição de presença na Web}

\begin{tabular}{|c|c|}
\hline Estágio & Características \\
\hline I - Presença Emergente & $\begin{array}{l}\text { Presença na web por meio de um website oficial, } \\
\text { um portal nacional ou uma home page oficial; } \\
\text { links para os ministérios do governo, governos } \\
\text { estaduais e locais, administração indireta; informa- } \\
\text { ção é limitada, básica e estática. }\end{array}$ \\
\hline II - Presença Aprimorada & $\begin{array}{l}\text { Serviços on line são aprimorados para incluir } \\
\text { bases de dados e fontes de informações atuais e } \\
\text { arquivadas, como políticas, leis e regulação, rela- } \\
\text { tórios, informativos e bases de dados para serem } \\
\text { baixadas pela Internet. O usuário pode procurar por } \\
\text { um documento e há função de ajuda e um mapa do } \\
\text { sítio é disponibilizado. }\end{array}$ \\
\hline III - Presença Interativa & $\begin{array}{l}\text { Provisão de serviços on line do governo entra } \\
\text { no modo interativo; facilidades para download } \\
\text { on line; link seguro; facilidade de assinatura } \\
\text { eletrônica; capacidade de áudio e vídeo para infor- } \\
\text { mação pública relevante. Os servidores públicos } \\
\text { podem ser contactados via e-mail, fax, telefone e } \\
\text { correio. O sítio é atualizado com grande regularidade. }\end{array}$ \\
\hline $\begin{array}{l}\text { IV - Presença } \\
\text { Transacional }\end{array}$ & $\begin{array}{l}\text { Usuários têm condições de conduzir transações } \\
\text { on line, como pagar multas por transgressões no } \\
\text { trânsito, impostos e taxas por serviços postais por } \\
\text { meio de cartão de crédito, bancário ou de débito. } \\
\text { Há algumas facilidades para licitar on line em con- } \\
\text { tratações públicas via links seguros. }\end{array}$ \\
\hline
\end{tabular}




\begin{tabular}{|l|l|}
\hline V - Presença em Rede & $\begin{array}{l}\text { Uma estrutura G2C (governo para cidadão) } \\
\text { baseada em uma rede integrada de agências } \\
\text { públicas para a provisão de informação, conheci- } \\
\text { mento e serviços. A ênfase está no feedback para } \\
\text { o governo. Um formulário de comentário na web } \\
\text { é disponibilizado. Um calendário de eventos } \\
\text { governamentais futuros existe com um convite do } \\
\text { governo à participação. Governo solicita feedback } \\
\text { por meio de mecanismos de pesquisa de opinião } \\
\text { on line; fóruns de discussão; e facilidades de } \\
\text { consulta on line. }\end{array}$ \\
\hline
\end{tabular}

Fonte: Nações Unidas (2003, p. 137).

Os estágios apresentados no Quadro 2 são ascendentes por natureza e elaborados de acordo com o nível de maturidade ou sofisticação da presença on line das administrações públicas dos estados-membros (Nações Unidas, 2003). Os países são classificados considerando se eles provêm produtos específicos e serviços sociais identificados como característicos de um determinado estágio.

Quanto à classificação em termos dos estágios apresentados no Quadro 2, deve-se esclarecer que cada país não se posiciona em apenas um determinado nível. A categorização em cinco estágios mostra qual o percentual de serviços on line que cada governo oferece em cada um desses patamares de desenvolvimento presença governamental na web. Por exemplo: os Estados Unidos, que possuem o maior Índice de Prontidão para Governo Eletrônico (Anexo A), utilizam em torno de $46 \%$ dos possíveis serviços transacionais on line (estágio IV do Quadro 2). A Suécia, por sua vez, segunda colocada nesse mesmo índice, utiliza apenas $20 \%$ do potencial transacional em serviços na Internet.

Além da categorização relativa aos estágios de oferta de serviços públicos na Internet, as Nações Unidas realizaram em 2003 uma pesquisa, intitulada UN Global E-government Survey 2003, que ampliou um estudo anterior concluído em 2002 (Nações Unidas, 2002). Nessa nova pesquisa, que englobou a totalidade dos 191 estados-membros ${ }^{1}$ da organização (Nações Unidas, 2003), foram utilizados dois indicadores para identificar o grau de desenvolvimento dos países em termos de governo eletrônico, os quais expressam o atual estágio das nações em relação a essa política: 1) índice de prontidão para governo eletrônico e 2) índice de e-participação.

Este artigo trata do primeiro desses índices (detalhado no Quadro 3 Anexo A), que representa a capacidade genérica ou aptidão do setor público em usar as tecnologias de informação e comunicação (TIC) para integrar serviços públicos e oferecê-los à sociedade, provendo informação de qualidade e ferramentas de comunicação efetivas que dêem suporte ao desenvolvimento humano. 


\section{Posicionamento do Brasil em relação aos demais países}

No Anexo A, os dados relativos ao Brasil, extraídos do World Public Sector Report 2003 (Nações Unidas, 2003), são citados em conjunto com os de outros países que possuem programas de governo eletrônico em estágios similares, quais sejam, Argentina, Chile e México. São mencionados, ainda, os dados do país mais bem posicionados no respectivo índice e daquele que ocupa a última posição, apenas para fins de posicionamento do Brasil no contexto global.

Considerando a pesquisa das Nações Unidas (2003), utilizada neste artigo como fonte para situar o Brasil ante o cenário mundial de e-gov, nota-se que houve um retrocesso na posição do país em relação ao que normalmente vinha sendo divulgado sobre seu Programa de Governo Eletrônico em estudos diversos, situação que é mais facilmente perceptível quando os dados do país são confrontados com os de outras nações que se encontram em estágios similares de desenvolvimento de iniciativas nessa área.

O otimismo que se demonstra na mídia e na literatura nacional não é condizente com os resultados da pesquisa das Nações Unidas (2003). Tal fato talvez seja explicado por algumas poucas iniciativas inovadoras Comprasnet e imposto de renda via Internet, por exemplo - que colocaram o Brasil em posições privilegiadas nos anos recentes, mas que não estão sendo capazes de manter o país bem posicionado no ranking. Deve-se observar que países que anteriormente se encontravam mais distanciados, em posições inferiores, agora se aproximam do Brasil, ou ultrapassam-no, por estarem investindo em tempos recentes de forma mais incisiva em seus projetos de e-gov.

As posições obtidas pelo Brasil, considerando o ranking e a estrutura dos índices adotada pelas Nações Unidas (2002, 2003), são explicadas, de modo preponderante, pelo fato de o país possuir uma presença governamental razoavelmente boa na Internet (refletida no índice de medida Web), mas fracos indicadores de infra-estrutura e de capital humano (relativos ao Índice de Infra-estrutura de Telecomunicações [Tabela 4 Anexo A] e de Capital Humano [Tabela 6 - Anexo A], respectivamente), que deslocam os índices gerais, como o índice de prontidão para E-governo (Tabela 1 - Anexo A), para patamares inferiores. No caso brasileiro, as condições da infra-estrutura podem limitar a contribuição do e-gov à governança, conforme alertam as Nações Unidas (2002, p. 36): "aspectos como telefonia, custos para o usuário, largura de banda, regulação das telecomunicações devem ser consideradas ao se levar em conta o potencial do governo eletrônico para transformar a governança". 
Ilustra-se a situação anteriormente mencionada, de uma superavaliação do potencial do país em serviços governamentais na Internet, por meio de uma comparação com a ascensão do Chile, por exemplo. Esse país, na pesquisa anterior das Nações Unidas (2002), figurava no índice E-gov em 35o lugar mundial e em 3임 luar na América

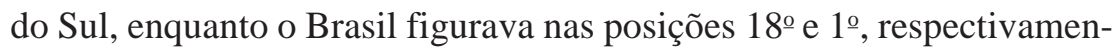
te. Na pesquisa mais recente (Nações Unidas, 2003), conforme Tabela 1 do Anexo A, o Chile aparece com relação ao índice de prontidão para Governo Eletrônico em 22ำ lugar no ranking mundial e como 1ํo colocado nas Américas do Sul e Central, superando o Brasil, que consta no ranking de 2003 como 41ㅇ e 4o colocado, respectivamente.

A empresa de consultoria Accenture (2003) aponta o decréscimo do Brasil no período concluído em 2002 - no caso de seu ranking próprio, de $19^{\circ}$ para 21ํ lugar no mundo - tendo sido causado, principalmente, pelo foco nas eleições presidenciais em outubro de 2002, além das eleições para deputados, senadores e aquelas realizadas nos estados (governadores e deputados estaduais), o que significou que as iniciativas de governo eletrônico cederam espaço e tiveram seu interesse reduzido frente a essa outra prioridade.

\section{Perspectivas para o governo eletrônico brasileiro}

Pode-se inferir que a Internet vem se consolidando como instrumento de crescimento econômico, alcançando dimensões dificilmente previsíveis anos atrás, seja como novo meio de organização das empresas, seja como mecanismo de universalização do acesso da população a bens culturais, razões pelas quais os países vêm discutindo a aplicação das TIC na administração pública, por meio do governo eletrônico. Eventos citados anteriormente, como o Terceiro Fórum Global, realizado em 2001, e a Cúpula Mundial sobre a Sociedade da Informação, em 2003, mostram a preocupação dos governos quanto à melhor utilização da Internet para o desenvolvimento econômico-social.

De um modo geral, o Brasil é usualmente visto como estando "bem colocado" nos rankings internacionais de e-gov, impressão que é alavancada por alguns poucos "casos de sucesso" - Comprasnet, Imposto de Renda pela Internet e eleições eletrônicas, por exemplo. Contudo, essa percepção positiva deve ser contraposta a limitações como a penetração restrita na sociedade - fruto da exclusão digital - e na própria cultura do serviço público (Medeiros, 2004).

Mesmo com uma trajetória descendente no período 2002/2003 ao menos à vista dos números das Nações Unidas $(2002,2003)$ e da 
Accenture (2003) - há a expectativa de que o Brasil aproveite seu potencial de governo on line a partir de 2004 e recupere as posições perdidas, considerando que seu índice de medida Web, que indica o grau em que os governos usam seu potencial de governo eletrônico, posiciona o país em 21 lugar no mundo - o que, para um país em desenvolvimento, pode ser considerada uma boa colocação.

Ações que venham a utilizar, por exemplo, os recursos do Fundo de Universalização dos Serviços de Telecomunicações (Fust) e que gerem, por conseguinte, reflexos em sítios de governo - foco do índice de medida Web - podem melhorar a avaliação global do país diante de seus "concorrentes" mais diretos, com ganhos para o indicador mais amplo, o Índice de Prontidão para Governo Eletrônico (Anexo A). O horizonte é promissor, pois a presença de rubricas específicas relacionadas a governo eletrônico - como inclusão digital e certificação digital - no orçamento federal a partir de 2004 mostra que a política vem, aos poucos, se institucionalizando no país (Medeiros, 2004).

\section{Nota}

1 Embora a pesquisa tenha sido feita com os 191 estados-membros das Nações Unidas, apenas 173 possuem presença na web.

\section{Referências bibliográficas}

ACCEnTURE. eGovernment Leadership: Engaging the Customer. Chicago: Accenture, 2003. Banco Mundial. A Definition of E.Government. World Bank's E-government Website. Disponível em <http://www1.worldbank.org/publicsector/egov/ definition.htm>. Acesso em 9 fev. 2003.

BRASIL. Sociedade da Informação no Brasil - Livro Verde. Organizado por Tadao Takahashi. Brasília: Ministério da Ciência e Tecnologia, 2000a.

Proposta de Política de Governo Eletrônico para o Poder Executivo

Federal. Grupo de Trabalho "Novas Formas Eletrônicas de Interação”. Brasília: Ministério do Planejamento, Orçamento e Gestão, 2000b.

. Decreto de 18 de outubro de 2000. Cria, no âmbito do Conselho de 
Brasil. Dois Anos de Governo Eletrônico - Balanço Preliminar. Brasília: Casa Civil da Presidência da República, Ministério do Planejamento, Orçamento e Gestão, Secretaria Executiva do Comitê Executivo do Governo Eletrônico, 2002.

Decreto de 29 de outubro de 2003. Institui Comitês Técnicos do Comitê Executivo do Governo Eletrônico e dá outras providências. Diário Oficial da União, Brasília, DF, 30 out. 2003.

Castells, Manuel. The Rise of the Network Society. Oxford: Blackwell Publishers, 1996.

Center for Technology In Government. Some Assembly Required: Building a Digital Government for the 21st Century. Albany: Center for Technology in Government, University at Albany, State University of New York, 1999.

Coelho, Espartaco M. Governo eletrônico e seus impactos na estrutura e na força de trabalho das organizações públicas. Revista do Serviço Público, Brasília, ano 52, n. 2, p. 111-138, abr./jun. 2001.

Cúpula Mundial sobre a Sociedade da Informação, 1., 2003. Genebra. Relatório da Fase de Genebra. Genebra: World Summit on the Information Society Executive Secretariat, 2004.

Grande, J. Ignacio C.; Araujo, María Carmen R.; Serna, Miquel S. La Necesidad de Teoría(s) sobre Gobierno Electrónico: uma propuesta integradora. In: Concurso de Ensayos y Monografías del Clad Sobre Reforma del Estado y Modernización de la Administración Pública, 16., 2002, Caracas. Anais eletrônicos. Caracas: Centro Latinoamericano de Administración para el Desarollo (CLAD), 2002. 1 CD-ROM.

Intosal. Auditing E-government. Viena: Intosai, Standing Committee on IT Audit, Task Force for Auditing E-Government, 2003. (International Organization of Supreme Audit Institutions).

Kumar, Krishan. Da Sociedade Pós-Industrial à Pós-Moderna: novas teorias sobre o mundo contemporâneo. Rio de Janeiro: Jorge Zahar, 1997.

MedeIros, Paulo Henrique R. Governo Eletrônico no Brasil: Aspectos Institucionais e Reflexos na Governança. Dissertação (Mestrado em Administração) - Programa de PósGraduação em Administração, Brasília: Universidade de Brasília, 318 f., 2004.

NAÇõES UnIDAS. Benchmarking E-Government: a global perspective. Nova York: United Nations - Division for Public Economics and Public Administration, American Society for Public Administration, 2002.

World Public Sector Report 2003: E-government at the Crossroads. Nova York: United Nations - Department of Economic and Social Affairs, Division for Public Administration and Development Management, 2003.

National Audit Office. Better Public Services through e-government. Londres: The Stationery Office, 2002.

OCDE. E-government: analysis framework and methodology. Paris: Organização para Cooperação e Desenvolvimento Econômico (OCDE), 2001.

SAto, Cláudio S. Utilizando a Internet na Administração Pública. Texto para Discussão, n. 22. Brasília: Escola Nacional de Administração Pública (ENAP), 1997.

Souza, Mauro Castro L. de. Política de Tecnologia da Informação no Brasil - Caminho para o século XXI. Brasília: NTC, 2002.

TAKAHASHI, Tadao. A sociedade da informação e a democracia eletrônica - O programa Sociedade da Informação: um balanço de atividades e perspectivas. In: Chahin, Ali et al. E-gov.br-A próxima revolução brasileira - Eficiência, qualidade e democracia: o governo eletrônico no Brasil e no mundo, p. 85-95. São Paulo: Prentice Hall, 2004.

Terceiro Fórum Global. Third Global Forum: Fostering Democracy and Development Through E-Government. Findings and Recommendations. Nápoles, mar. 2001. Disponível em <http://www1.oecd.org/puma/Egov/third_global_forum.pdf> Acesso em 10 fev. 2003. 
Tabela 1: Índice de Prontidão para Governo Eletrônico

\begin{tabular}{c|l|l}
\hline Posição no ranking do índice & País & Índice \\
\hline 1 & Estados Unidos & 0,927 \\
\hline 22 & Chile & 0,671 \\
\hline 30 & México & 0,593 \\
\hline 31 & Argentina & 0,577 \\
\hline 41 & Brasil & 0,527 \\
\hline 173 & Palau & 0,009 \\
\hline
\end{tabular}

Fonte: Nações Unidas (2003). 
Quadro 3: Estrutura do Índice de Prontidão para

Governo Eletrônico

\begin{tabular}{|l|l|}
\hline \multicolumn{2}{|l|}{ Índice de prontidão para Governo Eletrônico } \\
\hline Subíndice & Descrição do subíndice \\
\hline 1. Índice de medida web & $\begin{array}{l}\text { É um índice quantitativo que serve para medir } \\
\text { a aptidão genérica dos governos em empregar } \\
\text { o e-gov como uma ferramenta para informar, } \\
\text { interagir, transacionar e atuar em rede. Está } \\
\text { baseado no Modelo de Medição de Presença } \\
\text { na Web (Quadro 2). Os países são classifica- } \\
\text { dos tomando-se por base se produtos e } \\
\text { serviços específicos são providos on line } \\
\text { (presença ou ausência), sem que seja feita } \\
\text { uma avaliação da qualidade com que são } \\
\text { oferecidos. }\end{array}$ \\
\hline 2. Índice de infra-estrutura \\
É um índice composto, com pesos médios \\
oriundos de telecomunicações de 6 índices \\
primários, baseado em indicadores básicos \\
que definem a capacidade de infra-estrutura \\
de TIC de um país, a saber: 1) PCs/1.000 \\
pessoas; 2) usuários de Internet/1.000 \\
pessoas; 3) linhas de telefone/1.000 pessoas; \\
4) população on line/1.000 pessoas; 5) telefo- \\
nes celulares/1.000 pessoas e 6) TVs/1.000 \\
pessoas.
\end{tabular}

Fonte: Nações Unidas (2003). 
Tabela 2: Componentes do Índice de Prontidão para Governo Eletrônico

\begin{tabular}{|c|c|c|c|c|c|}
\hline \multirow{2}{*}{$\begin{array}{c}\text { Posição } \\
\text { no Ranking } \\
\text { do Índice }\end{array}$} & \multirow[t]{2}{*}{ País } & \multirow{2}{*}{$\begin{array}{c}\text { Índice de } \\
\text { prontidão } \\
\text { para Governo } \\
\text { Eletrônico }\end{array}$} & \multicolumn{3}{|c|}{ Subíndices } \\
\hline & & & $\begin{array}{c}\text { Índice } \\
\text { de medida } \\
\text { WEB } \\
\end{array}$ & $\begin{array}{c}\text { Índice de infra- } \\
\text { estrutura de } \\
\text { telecomunicações }\end{array}$ & $\begin{array}{c}\text { Índice } \\
\text { de capital } \\
\text { humano }\end{array}$ \\
\hline 1 & $\begin{array}{c}\text { Estados } \\
\text { Unidos }\end{array}$ & 0,927 & 1,00 & 0,801 & 0,98 \\
\hline 22 & Chile & 0,671 & 0,838 & 0,275 & 0,90 \\
\hline 30 & México & 0,593 & 0,808 & 0,132 & 0,84 \\
\hline 31 & Argentina & 0,577 & 0,624 & 0,187 & 0,92 \\
\hline 41 & Brasil & 0,527 & 0,576 & 0,174 & 0,83 \\
\hline 173 & Palau & 0,009 & 0,026 & 0,000 & 0,00 \\
\hline
\end{tabular}

Fonte: Nações Unidas (2003).

Tabela 3: Índice de medida Web

\begin{tabular}{c|l|c}
\hline Posição no ranking do índice & País & Índice \\
\hline 1 & Estados Unidos & 1,000 \\
\hline 2 & Chile & 0,838 \\
\hline 4 & México & 0,808 \\
\hline 15 & Argentina & 0,624 \\
\hline $\mathbf{2 1}$ & Brasil & $\mathbf{0 , 5 7 6}$ \\
\hline 173 & Grenada & 0,004 \\
\hline
\end{tabular}

Fonte: Nações Unidas (2003).

Tabela 4: Índice de infra-estrutura de telecomunicações

\begin{tabular}{c|l|l}
\hline Posição no ranking do índice & País & Índice \\
\hline 1 & Suécia & 0,846 \\
\hline 44 & Chile & 0,275 \\
\hline 63 & Argentina & 0,187 \\
\hline 66 & Brasil & $\mathbf{0 , 1 7 4}$ \\
\hline $\mathbf{7 3}$ & México & 0,132 \\
\hline 191 & Palau & 0,000 \\
\hline
\end{tabular}

Fonte: Nações Unidas (2003). 
Tabela 5 - Indicadores Primários do Índice de Infra-estrutura de Telecomunicações

\begin{tabular}{|c|c|c|c|c|c|c|}
\hline \multirow{2}{*}{$\begin{array}{c}\text { Posição } \\
\text { no } \\
\text { Ranking } \\
\text { do Índice }\end{array}$} & \multirow[t]{2}{*}{ País } & \multirow[t]{2}{*}{ Índice } & \multicolumn{4}{|c|}{ Indicadores Primários(I) } \\
\hline & & & $\begin{array}{c}\mathrm{PCs} / 1.000 \\
\text { pessoas }\end{array}$ & $\begin{array}{l}\text { Índice } \\
\text { PC }\end{array}$ & $\begin{array}{c}\text { Usuários de } \\
\text { Internet/1.000 } \\
\text { pessoas }\end{array}$ & $\begin{array}{l}\text { Índice } \\
\text { Internet }\end{array}$ \\
\hline 1 & Suécia & 0,846 & 561,2 & 0,738 & 573,074 & 0,943 \\
\hline 44 & Chile & 0,275 & 119,3 & 0,157 & 201,415 & 0,331 \\
\hline 63 & Argentina & 0,187 & 82 & 0,108 & 112,022 & 0,184 \\
\hline 66 & Brasil & 0,174 & 74,8 & 0,098 & 82,241 & 0,135 \\
\hline 73 & México & 0,132 & 68,7 & 0,090 & 45,774 & 0,075 \\
\hline 191 & Palau & 0,000 & 0 & 0,000 & 0,000 & 0,000 \\
\hline \multirow{2}{*}{$\begin{array}{c}\text { Posição } \\
\text { no } \\
\text { Ranking } \\
\text { do Índice }\end{array}$} & \multirow[t]{2}{*}{ País } & \multirow[t]{2}{*}{ Índice } & \multicolumn{4}{|c|}{ Indicadores Primários(II) } \\
\hline & & & $\begin{array}{c}\text { Linhas de } \\
\text { telefone/1.000 } \\
\text { pessoas } \\
\end{array}$ & Índice & $\begin{array}{c}\text { População on } \\
\text { line } 1.000 \\
\text { pessoas } \\
\end{array}$ & Índice \\
\hline 1 & Suécia & 0,846 & 720,2 & 0,782 & 699,0 & 1,000 \\
\hline 44 & Chile & 0,275 & 230,4 & 0,250 & 200,2 & 0,286 \\
\hline 63 & Argentina & 0,187 & 218,8 & 0,238 & 103,8 & 0,148 \\
\hline 66 & Brasil & 0,174 & 223,2 & 0,242 & 68,4 & 0,098 \\
\hline 73 & México & 0,132 & 146,7 & 0,159 & 33,8 & 0,048 \\
\hline 191 & Palau & 0,000 & 0 & 0,000 & 0 & 0,000 \\
\hline \multirow[b]{2}{*}{$\begin{array}{c}\text { Posição } \\
\text { no } \\
\text { Ranking } \\
\text { do Índice }\end{array}$} & \multirow{2}{*}{ País } & \multirow{2}{*}{ Índice } & \multicolumn{4}{|c|}{ Indicadores Primários(III) } \\
\hline & & & $\begin{array}{c}\text { Telefones } \\
\text { celulares/ } \\
1.000 \text { pessoas }\end{array}$ & Índice & $\begin{array}{c}\text { TVs/1.000 } \\
\text { pessoas }\end{array}$ & Índice \\
\hline 1 & Suécia & 0,846 & 885,0 & 0,873 & 574 & 0,656 \\
\hline 44 & Chile & 0,275 & 428,3 & 0,423 & 242 & 0,277 \\
\hline 63 & Argentina & 0,187 & 177,6 & 0,175 & 293 & 0,335 \\
\hline 66 & Brasil & 0,174 & 200,6 & $\mathbf{0 , 1 9 8}$ & 343 & 0,392 \\
\hline 73 & México & 0,132 & 254,5 & 0,251 & 283 & 0,323 \\
\hline 191 & Palau & 0,000 & 0 & 0,000 & 0 & 0,000 \\
\hline
\end{tabular}

Fonte: Nações Unidas (2003).

\section{Tabela 6: Índice de capital humano}

\begin{tabular}{c|l|l}
\hline Posição no ranking do índice & País & Índice \\
\hline 1 & Suécia & 0,99 \\
\hline 30 & Argentina & 0,92 \\
\hline 44 & Chile & 0,90 \\
\hline 78 & México & 0,84 \\
\hline $\mathbf{8 7}$ & Brasil & $\mathbf{0 , 8 3}$ \\
\hline 173 & Níger & 0,16 \\
\hline
\end{tabular}

Fonte: Nações Unidas (2003). 
Revista do

Serviço

Público

Ano 55

Números 1 e 2

Jan-Jun 2004

Paulo Henrique

Ramos Medeiros

é Analista de

Controle

Externo do

Tribunal de

Contas da

União e mestre em administração pela UnB.

Tomás de

Aquino

Guimarães é

professor do

programa de

pós-graduação

em adminis-

tração da UnB

e doutor em

sociologia pela

USP.

Contato: paulohr@ tcu.gov.br

tomas@ unb.br

\section{O estágio do governo eletrônico no Brasil em relação ao contexto mundial Paulo Henrique Ramos Medeiros e Tomás de Aquino Guimarães}

O artigo explora o estágio de implementação do governo eletrônico no Brasil, apoiando-se no ranking das Nações Unidas para discutir o posicionamento do país diante do contexto global de e-gov. É apresentado o conceito de governo eletrônico, sendo abordados, em seguida, os programas do governo federal brasileiro relacionados com essa política. Conclui-se que o Brasil alcançou, até 2002, boas avaliações em seu programa de e-gov como resultado, especialmente, da implementação de alguns "casos de sucesso" - como o Comprasnet e o imposto de renda pela Internet. A partir de 2003, entretanto, sua trajetória passou a ser descendente, cedendo lugar a outros países que se encontravam, anteriormente, em posições inferiores no ranking. Ao final do artigo é feita uma reflexão sobre as perspectivas para o e-gov no país, vislumbrando-se um futuro capaz de recolocar o Brasil em posição mais próxima a dos países que possuem programas de e-governo em estágios mais avançados de desenvolvimento.

\section{La práctica del gobierno electrónico en Brasil en relación al contexto mundial Paulo Henrique Ramos Medeiros y Tomás de Aquino Guimarães}

El artículo explora la práctica del gobierno electrónico en Brasil, apoyando-se en el ranking de las Naciones Unidas para discutir el posicionamiento del país frente al contexto global de e-gov. Es presentado el concepto de gobierno electrónico, siendo abordados, enseguida, los programas del gobierno federal brasileño para esa política. Concluye-se que Brasil alcanzó buenas evaluaciones hasta 2002 como resultado, en especial, de la implementación de algunos "casos de éxito" - como el Comprasnet y el impuesto de renta por Internet. A partir de 2003, sin embargo, su trayectoria pasó a ser descendiente, cediendo lugar a otros países que se encontraban, anteriormente, en posiciones inferiores en el ranking. $\mathrm{Al}$ final, es hecha una reflexión sobre las perspectivas para el e-gov en el país, vislumbrando-se un futuro capaz de recolocar Brasil en posición más cercana la de los países que poseen programas de e-gobierno en prácticas más avanzadas de desarrollo.

\section{The stage of development of e-government in Brazil in relation to the world- wide context}

\section{Paulo Henrique Ramos Medeiros and Tomás de Aquino Guimarães}

The article explores the stage of development of electronic government in Brazil, using the United Nations ranking to discuss the positioning of the country considering the global context of e-gov. It is presented the concept of electronic government, being approached, right away, the Brazilian federal government programs related to that policy. The main conclusions are that Brazil reached good evaluations up to 2002 especially as a result of the implementation of some "success cases" - like Comprasnet and the revenue service on the Internet. From 2003, however, its trajectory started to be descending, yielding place to other countries that were, previously, in lower positions in ranking. After all, the article presents a reflection about the perspectives for the Brazilian e-gov, glimpsing a future capable of putting Brazil in a better position, closer to the countries that possess egovernment programs in more advanced stages of development. 